\title{
THE INFLUENCE OF SPACE LAYOUT DESIGN ON OCCUPANT'S ENERGY BEHAVIOUR
}

\author{
Elham Delzendeh ${ }^{1}$ and Song $\mathrm{Wu}^{2}$
}

\begin{abstract}
In the past 15 years, the calculation of energy consumption in buildings has become more and more critical due to growing scientific and political concerns to respond to the challenges of global warming and climate change. The estimation of energy demand in buildings is now often a required process during the design stages. Yet, there is a considerable discrepancy between the predicted and actual energy consumption in buildings due to occupants' energy consumption activities. Occupants' presence and their interactions with building systems play a significant role in building's energy consumption; however, it has been overlooked in building energy predictions. Different studies have been performed with the aim to better understand the parameters affecting occupant's energy behaviour with special focus on climatic, economics, regulations and social/personal aspects. Interior design of the space, too, has various impacts on behaviours of occupants and their interactions with building systems which affects the energy consumption of buildings. Space layout is a feature within interior design of space which influences occupants' movement and choices of intentional behaviours. This paper highlights a gap in the knowledge by introducing "space layout" features as an influential factor on occupant's energy behaviours and propose an analytical method to study the impact of the space layout on occupants' energy behaviours. Understanding the impact will help designers influence the sustainable behaviour through the design of interior spaces.
\end{abstract}

Keywords: Space layout design, energy consumption, occupant's behaviour

\section{INTRODUCTION: OCCUPANTS' ENERGY BEHAVIOURS}

It has been broadly acknowledged that the occupant's behaviour plays essential role in the energy consumption of buildings, however, it has been constantly overlooked in building energy predictions (Maier et al. 2009, Fabi et al. 2013, Schakib-Ekbatan et al. 2015, Martinaitis et al. 2015, HUB 2015, Yang et al. 2015, Calì et al. 2016). Occupants interact with building systems to acquire thermal, visual and acoustic comfort, as well as, improving the indoor air quality. HVAC systems, electrical devices and lighting which are responsible to provide thermal and visual comfort for the occupants, are the greatest sources of energy consumption in buildings (Harish and Kumar 2016).

O'Brien and Gunay (2015) mentioned oversimplification of occupant behaviour as the main cause of inaccuracy in energy consumption predictions in buildings. The impact of occupants on energy consumption in buildings has been studied extensively and the research area is going forward rapidly, however, those studies have not considerably materialised the reduction of the gap between predicted and actual energy consumption in buildings and there is a need for further studies in order to better understand occupants' behaviours. These studies have adopted agent based or/and stochastic approaches to

$1 \mathrm{PhD}$ candidate, School of Art, Design and Architecture, University of Huddersfield, UK, E.Delzendeh@hud.ac.uk

2 Professor of Surveying and IT, Acting Director of Teaching and Learning, School of Art, Design and Architecture, University of Huddersfield, UK, S.wu@hud.ac.uk 
improve the deterministic energy models used in the existing energy simulation tools (Ahn and Park 2016). Stochastic methods consider parameters and probabilities derived from the collected data of a certain case and have been implemented by various scholars (Jang and Kang 2016, Page et al. 2007). Agent based approaches focus on occupants' intentions and perceptions (Ahn and Park 2016). There has been also a third approach using a combination of both agent based and stochastic methods, such as: Multiple Modules (MuMo) model proposed by Liao and Barooah (2010) to simulate multiple occupants' movements between multiple zones. In another classification, Zhao et al. (2012) mentioned model simulation method and statistical analysis as the two methods used to determine the energy efficiency in buildings: model simulation methods use the integration of actual observed data and the mathematical calculation of building energy consumption and statistical analysis methods use great number of data and generate information regarding energy consumption by analysing them.

Occupants' energy behaviours refer to the occupants activities that affect the energy consumption of buildings including: using appliances, opening windows, using hot water, using HVAC system (e.g. adjusting thermostat set-points), using lighting and adjusting blinds. Occupants have impacts on the energy consumption of the building not only by their active energy use, but also, by their presence and production of metabolic heat, known as passive energy behaviour, which increases the internal heat gain of the building (Figure 1).

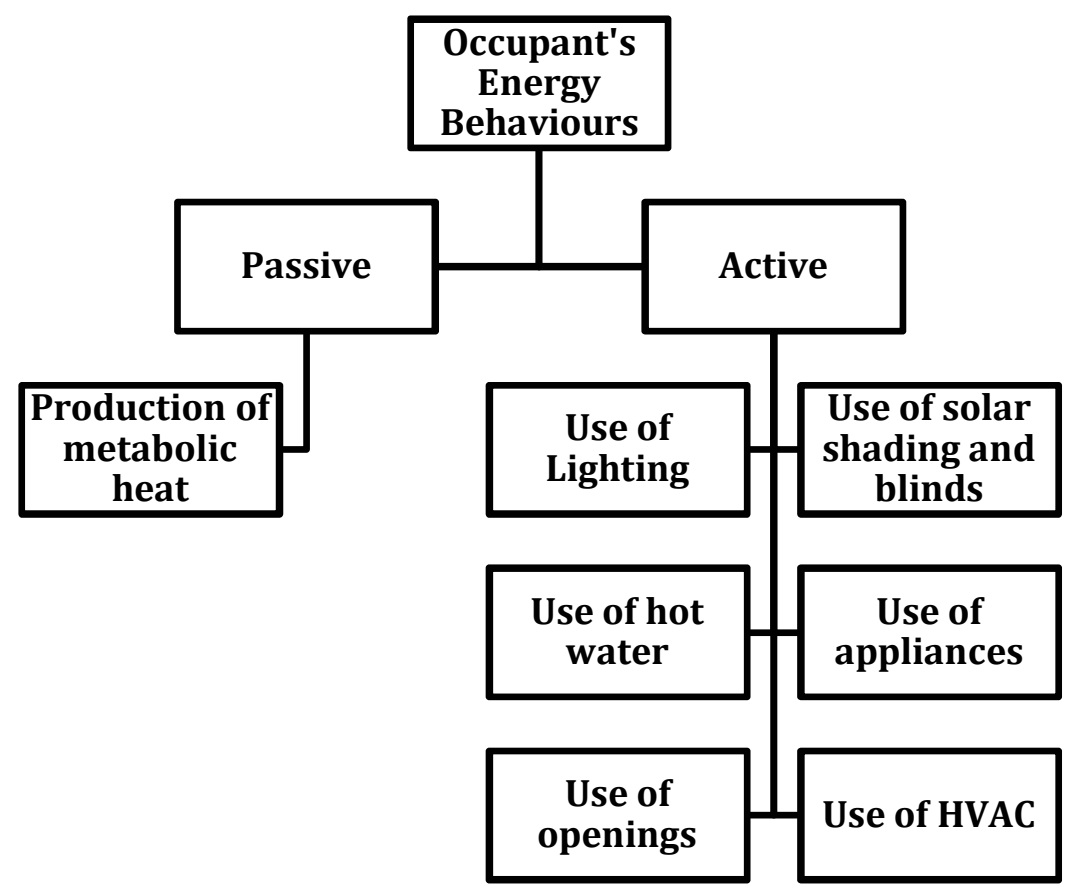

Figure 1: Occupant's active and passive energy behaviours

Occupants' energy behaviour is very complex as it is dependent on multiple factors. A comprehensive state-of-art review of more than 100 publications undertaken by the authors on the influence of occupants' behaviour on building energy consumption suggests that the climatic (environmental, physical), personal (physiological and psychological), social, economic and legal parameters together with building type and design features are the key factors studied by various researchers around the world. Insufficiency of knowledge about influential factors on energy consumption in buildings are considered as the most important obstacles to improve energy performance of buildings (Fabi et al. 2011). 
Figure 2 displays the frequency of each of the aforementioned factors being discussed among the reviewed studies.

The impact of building conditions and specific design features have been considered in some studies (Karjalainen 2016, Ouf et al., 2016, Goldstein et al. 2011, Agha-Hossein et al. 2013). Interior design of the space has various impact on occupants and their interactions with building systems, so it could affect the energy consumption of buildings. Several studies have underlined the influence of interior design of the space on occupant's behaviour (Caan 2011, Augustin 2009), however, its link to the occupant's energy behaviour has not been fully understood. Therefore, this paper proposes to study the design of the space layout and how it could impact on energy consumption of building.

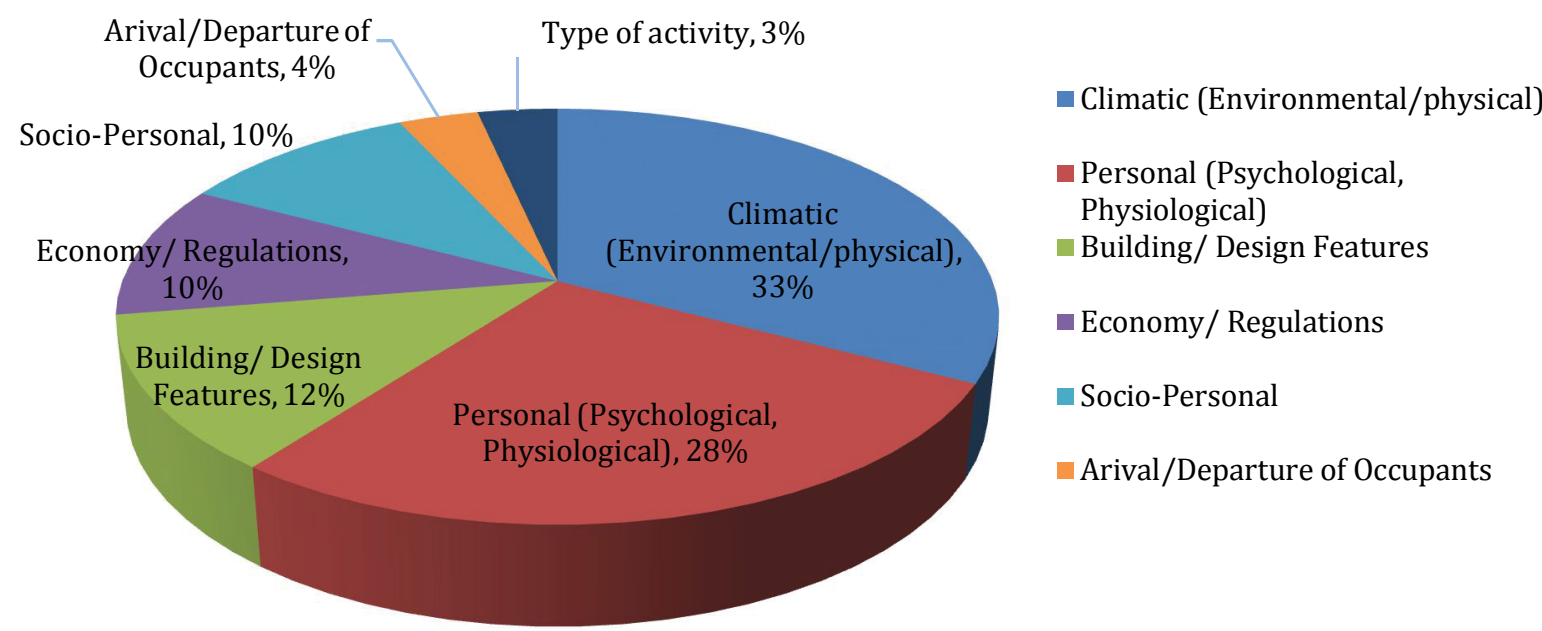

Figure 2: Frequency of influential parameters on occupants' energy behaviours, reviewing more than 100 relevant publications

\section{INTERIOR DESIGN, SUSTAINABLE BEHAVIOUR AND ENERGY CONSUMPTION}

\subsection{Sustainable interior design}

One of the topics that links the current studies between interior design and energy is sustainability in interior design. Current applications of sustainability in interior design are mainly focusing on the use of green and recyclable materials and energy efficient building systems and components (Lee et al. 2013). Sustainability concept in building construction does not only focus on design and construction of buildings, but also, on operation, maintenance, and decommission stages. However, operation considerations and occupant's actual energy behaviour within interior spaces are not being discussed sufficiently in the sustainable interior design practices.

\subsection{Sustainable behaviour}

The term "design for sustainable behaviour" that is mostly discussed in product design, remarks how designers can influence more sustainable practices by the users (Lilley 2009, Wilson et al. 2013, Lockton et al. 2013). It aims to promote the sustainable use of products by considering series of strategies during the design stage to encourage sustainable use of the product (Lilley 2009). Lockton et al. (2013) used an example to describe how interior 
design can persuade occupants to make more sustainable and energy saving decisions: based on the findings of a study by Energy Saving Trust (2003), if people close curtains at night, they can reduce a considerable amount of heat loss in the houses. Therefore, the designer can help the occupants by considering this issue during the design stage (Lockton et al. 2013). O'Brien and Gunay (2015) mentioned that designers know that occupant behaviour plays a crucial role to achieve sustainability in design, but, they are not aware of their own role as designers to encourage the sustainable behaviour by their design. The findings of a research study by Niedderer et al. (2016) identified a distinct gap between existing theories in "design for behaviour change" and its actual practice. Niedderer et al. (2016) suggested that the gap is due to the lack of proper case studies and validation methods and multidisciplinary approaches.

\section{THE IMPACT OF INTERIOR DESIGN ON OCCUPANTS' ENERGY BEHAVIOURS}

Interior design is defined as the interdisciplinary artistic practice of decorating and manipulating spaces, placing furniture and modifying the surfaces to help the architecture function well (Brooker and Stone 2010). Pile (2007) defines the term interior design as a set of design plans applied into living spaces to make them suitable for their various functions. Interior design features affecting occupants' energy behaviours can be divided in two main categories: first, all "psychological" aspects which influence occupant's perception of the space; second, non-psychological features such as "space layout or physical arrangement of the interior space" that affects occupant's action scenario and their choices of intentional activities (Figure 3).

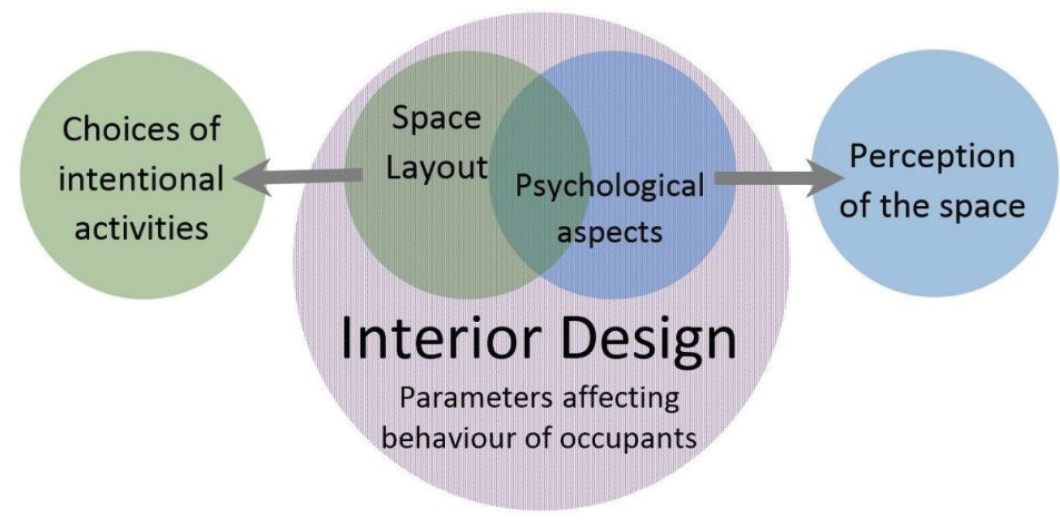

Figure 3: Interior design aspects affecting occupant's energy behaviour

The occupant's perception of the space is influenced by its design characteristics like: colours, materials, light, form and shape (Arnheim 2004) which are considered as the psychological features. Augustin (2009) stated that the design of a space impacts the mental and psychological state of occupants and shapes their attitudes. People try to elude unpleasant conditions and search for pleasant ones (Cabanac 1971), as well as, looking for comfort. The pleasure and comfort within living environments are deeply related to people's perceptions of the space which affect their behaviours. Various place scientists and environmental psychologists study how places with all their psychological characteristics are being used by people (Augustin 2009).

The physical arrangement of the space, also, has impacts on the occupant's energy behaviour by moderating and manipulating their action scenarios. Goldstein et al. (2011) 
remarked the influence of space layout on occupants' choices of activities and their locations. Physical arrangement or space layout is the special order and embellishment of objects and furniture within the space. Space layout design is governed by space form and architectural concept and it aims to place interior objects in their proper locations while reducing cost per time and improving design quality (Dino 2016).

\section{LINKING SPACE LAYOUT DESIGN AND OCCUPANT'S ENERGY BEHAVIOUR}

Space layout design is a significant stage in interior design and architecture which consists of series of design choices to reach the best possible arrangement in space that contents different space functions and purposes (Dino 2016). In a research study, Goldstein et al. (2011) made a model to predict the occupancy in different locations of the same space with different types of activities and functions. In this regard, they suggested there is a link between the type of activity and its location inside the space which highlights the impacts of space layout on occupants' behaviours.

This paper is proposing an analytical method to study the impact of interior design space layout on occupants' energy behaviour. In this regard, the interior space will be divided into destinations, circulations and energy consumption spots (Figure 4). Destinations are the locations in the space with special functions that occupants could go to or stay to perform certain activity; circulations are the paths to go from one destination to another; and energy behaviour spots are the location of all building elements or systems (e.g. windows and HVAC set-points) from where occupants perform their active energy behaviours. Both destination and circulation could affect the passive energy behaviour through the presence of the occupants.

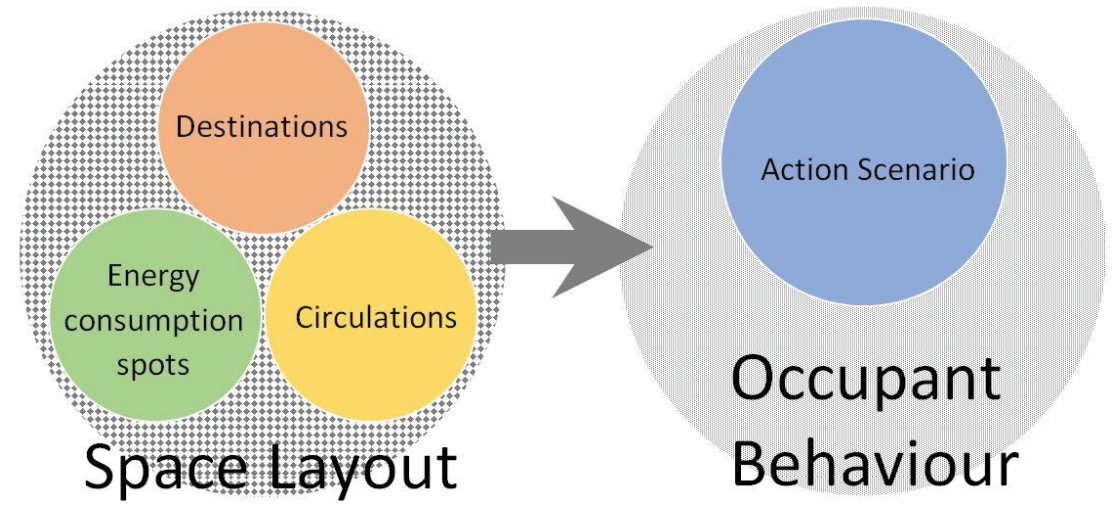

Figure 4: The influence of interior design space layout on occupant's energy behaviour

Using the following simplified analytical model of the space layout as an example will be useful to predict the most probable patterns of occupants' presences, movements and active energy behaviours. The simplified model considers the main routes within the interior space based on the existing starting points and destinations. Figure 5 shows an example of a simplified model of an office room. 


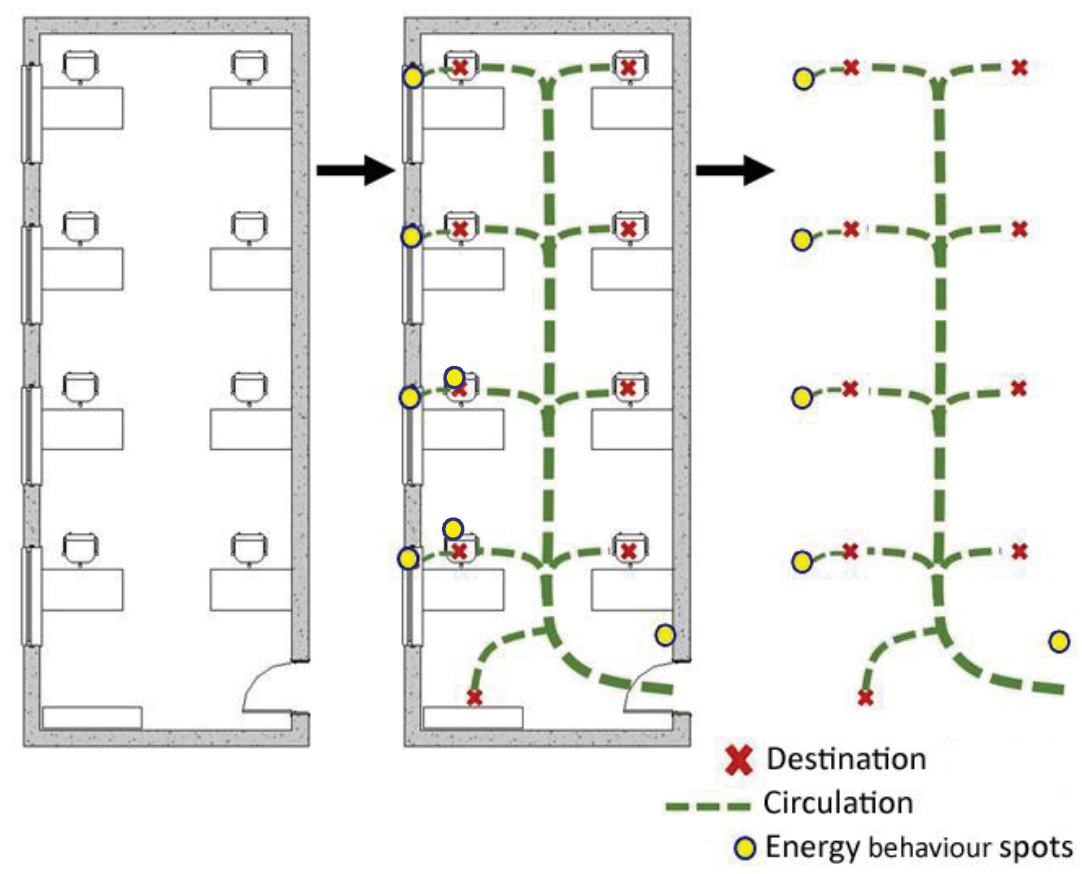

Figure 5: An example of simplified interior design space layout

One of the questions the future stage of this research is if ease of use of building systems (such as windows, blinds and HVAC control points) can be considered as encouraging parameters towards more occupant' interactions with them, then, it can be hypothesised that the distance (or accessibility) between occupant's destination and the building system can be considered as one of the variables. If it is less, it is more probable that the occupant will interacts with it. In other words, if a window is being associated with a desk in an office building, the probability that the occupant interacts with the window is more because of ease of use (less distance) and more disturbance factors (such as glare or draught). On the other hand, the occupant might accept more discomfort before taking active energy behaviour like opening a window or adjusting the blinds, if such action is more difficult to perform, for example if the occupant is far from the window or blind. Figure 6 displays three space layout scenarios of an office room where the number of occupants is the same.

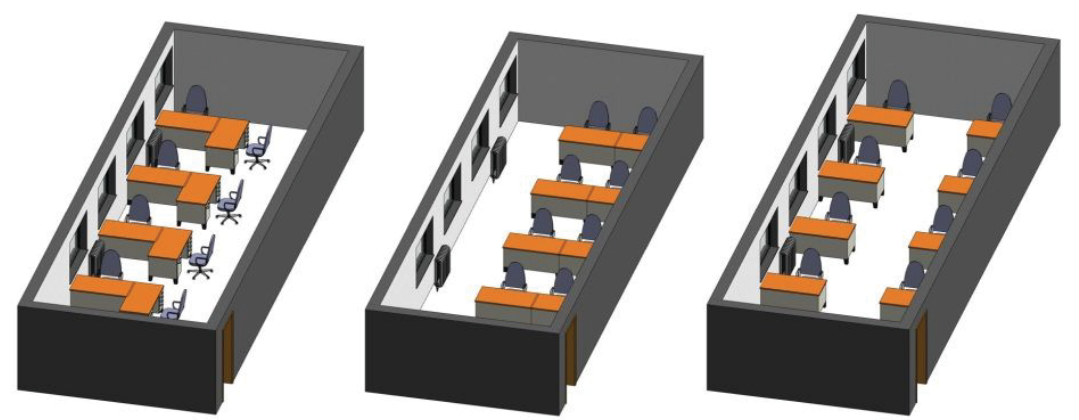

Figure 6: Different space layout scenarios

The aim of the analytical model to establish the quantifiable relationships between occupants and building elements in a space layout where could have impact on occupant active energy behaviours. The passive energy use can also be established through the pattern of circulations. 


\section{CONCLUSIONS}

The paper highlights a research gap in term of the link between the interior space layout and occupants' energy behaviour. The space layout localises occupants' activities and influences their choices of activities and potential behaviour. Therefore, there is a link between interior design of the space and occupants' behaviours. Space layout can affect active and passive engagement of occupants in the space. This paper proposes an analytical method to introduce new space elements as destinations, circulations and energy behaviour spots. Destinations are those locations within the space that active engagement of occupants take place, and circulations, are the path from one destination to another which contains occupant's passive engagement with the space. Energy behaviour spots specify the locations where occupants' active energy behaviours happen. By studying the relationship between those 3 elements (destinations, circulations and energy behaviour spots) and their probabilities on occupants' choices of energy behaviour, we can simulate the energy behaviours and estimate the energy consumptions in the energy analysis tool. Next stage of the research will include data collection and quantitative outputs through case studies to measure the impact of the distance between occupants' destinations and building behaviour spots on their active energy behaviours, as well as, quantifying disturbance factors of building elements for different destination scenarios within the interior space and their link with occupants' active energy behaviour.

\section{REFERENCES}

Agha-Hossein, M. M., El-Jouzi, S., Elmualim, A. A., Ellis, J. and Williams, M. (2013). Postoccupancy studies of an office environment: Energy performance and occupants' satisfaction. Building and Environment, 69, 121-130. doi: 10.1016/j.buildenv.2013.08.003

Arnheim, R. (2004). Art and visual perception: a psychology of the creative eye (Vol. New version.). Berkeley, Calif;London;: University of California Press.

Augustin, S. (2009). Place advantage: applied psychology for interior architecture. Hoboken, N.J: John Wiley \& Sons.

Brooker, G. and Stone, S. (2010). What is interior design? Hove;Mies;: RotoVision.

Caan, S. (2011). Rethinking Design and Interiors, Human Beings in the Built Environment. London: Laurence King.

Cabanac, M. (1971). Physiological Role of Pleasure. Science, 173(4002), 1103-1107. doi: 10.1126/science.173.4002.1103

Calì, D., Osterhage, T., Streblow, R. and Müller, D. (2016). Energy performance gap in refurbished German dwellings: Lesson learned from a field test. Energy and Buildings, 127, 1146-1158. doi: 10.1016/j.enbuild.2016.05.020

Dino, I. G. (2016). An evolutionary approach for 3D architectural space layout design exploration. Automation in Construction, 69, 131-150. doi: 10.1016/j.autcon.2016.05.020

EUROSTAT. (2015). Consumption of energy. http://ec.europa.eu/: EUROSTAT.

Fabi, V., Andersen, R. V., Corgnati, S. P. and Olesen, B. W. (2013). A methodology for modelling energy-related human behaviour: Application to window opening behaviour in residential buildings. Building Simulation, 6(4), 415-427. doi: 10.1007/s12273-0130119-6 
Goldstein, R., Tessier, A. and Khan, A. (2011). Space layout in occupant behavior simulation. Paper presented at the 12th Conference of International Building Performance Simulation Association, Sydney.

HUB, Z. C. (2015). Post-occupancy Evaluation, Rowner Research Project Phase Two. Zero Carbon HUB.

Karjalainen, S. (2016). Should we design buildings that are less sensitive to occupant behaviour? A simulation study of effects of behaviour and design on office energy consumption. Energy Efficiency, 1-14. doi: 10.1007/s12053-015-9422-7

Lee, E., Allen, A. and Kim, B. (2013). Interior Design Practitioner Motivations for Specifying Sustainable Materials: Applying the Theory of Planned Behavior to Residential Design: MOTIVATIONS FOR SUSTAINABLE RESIDENTIAL DESIGN. Journal of Interior Design, 38(4), 1-16. doi: 10.1111/joid.12017

Lilley, D. (2009). Design for sustainable behaviour: strategies and perceptions. Design Studies, 30(6), 704-720. doi: 10.1016/j.destud.2009.05.001

Lockton, D., Harrison, D. and Stanton, N. A. (2013). Exploring Design Patterns for Sustainable Behaviour. The Design Journal, 16(4), 431-459. doi: 10.2752/175630613X13746645186124

Maier, T., Krzaczek, M. and Tejchman, J. (2009). Comparison of physical performances of the ventilation systems in low-energy residential houses. Energy \& Buildings, 41(3), 337-353. doi: 10.1016/j.enbuild.2008.10.007

Martinaitis, V., Zavadskas, E. K., Motuziene, V. and Vilutiene, T. (2015). Importance of occupancy information when simulating energy demand of energy efficient house: A case study. Energy and Buildings, 101, 64-75. doi: 10.1016/j.enbuild.2015.04.031

Moxon, S. N. (2012). Sustainability in interior design (Vol. 1). London: Laurence King.

Niedderer, K., Ludden, G., Clune, S. J., Lockton, D., Mackrill, J., Morris, A. and Hekkert, P. (2016). Design for behaviour change as a driver for Sustainable Innovation: Challenges and opportunities for implementation in the private and public sectors. International Journal of Design, 10(2), 67-85.

O’Brien, W. and Gunay, H. B. (2015). Mitigating office performance uncertainty of occupant use of window blinds and lighting using robust design. Building Simulation, 8(6), 621-636. doi: 10.1007/s12273-015-0239-2

Ouf, M., Issa, M. and Merkel, P. (2016). Analysis of Real-Time Electricity Consumption in Canadian School Buildings. Energy and Buildings. doi: 10.1016/j.enbuild.2016.07.022

Pile, J. F. (2007). Interior design (Vol. 4th). Harlow: Prentice Hall.

Schakib-Ekbatan, K., Çakici, F. Z., Schweiker, M. and Wagner, A. (2015). Does the occupant behavior match the energy concept of the building? - Analysis of a German naturally ventilated office building. Building and Environment, 84, 142-150. doi: 10.1016/j.buildenv.2014.10.018

Trust, E. S. (2003). Don't let your home get away with it - Media facts. from http://www.energysavingtrust.org.uk/

Wilson, G. T., Lilley, D. and Bhamra, T. A. (2013). Design feedback interventions for household energy consumption reduction. Paper presented at the 16th Conference of the European Roundtable on Sustainable Consumption and Production (ERSCP) \& 7th Conference of the Environmental Management for Sustainable Universities (EMSU).

Yang, J., Santamouris, M. and Lee, S. E. (2015). Review of occupancy sensing systems and occupancy modeling methodologies for the application in institutional buildings. Energy and Buildings. doi: 10.1016/j.enbuild.2015.12.019 